\title{
Effects of Tobacco Chewing and Smoking and Its Relationship with Perio- dontal Health
}

\author{
Farzana Sajjad $^{1, *}$, Moona Mumtaz ${ }^{1}$ and Ramsha Sajjad ${ }^{2}$ \\ ${ }^{1}$ Bahria University Medical and Dental College, Karachi, Pakistan. \\ ${ }^{2}$ Altamash Institute of Dental Medicine, Karachi, Pakistan.
}

\begin{abstract}
Tobacco smoking and chewing is a significant contributing factor of periodontal health. Tobacco consumption increases the probability of periodontal disease by affecting the periodontal attachment, pocket formation as well as bone loss. The purpose of this study was to examine the effects of tobacco consumption and its relationship with periodontal health. This is a cross-sectional study of 169 participants chosen from an urban population with an age distribution from 15 to 65 years. Among the study population, 130 were males and 39 were females with the data collected and analyzed by SPSS version 16. The study revealed a significant relationship between the use of tobacco and gingival index, the plaque index, and the community periodontal index of treatment needs. According to the results, there was a high correlation between intake of tobacco and the gingival score.
\end{abstract}

Keywords: Diabetes mellitus, Gingival, Heart disease, Periodontal disease, Smoking, Tobacco. doi.org/10.21089/njhs.23.0106

\section{INTRODUCTION}

An individuals' periodontal health has been identified to be affected by tobacco chewing and smoking. Tobacco intake is related with increasing rate of multiple health complications which also includes loss of periodontal bone and the loss of the periodontal attachment and bone formation. In addition, tobacco smoking and chewing has been connected with the masking of the gingival swelling symptoms. Research has also contributed that tobacco smokers suffering from the periodontitis disease respond negatively to treatment. The major objective of this research is to identify the effects of tobacco intake and its relation with the periodontal diseases.

\section{LITERATURE REVIEW}

A number of oral conditions have been identified to be related with tobacco smoking and chewing. The initial studies have showed a positive correlation between tobacco smoking and chewing with periodontitis and other health complications [1]. In addition, smoking of tobacco is a crucial element that affects the refractory periodontal disease [2]. Periodontal bone loss, loss of teeth and periodontal attachment loss are all increasing due to tobacco smoking and chewing.

Gingivitis is a disease that has been related with smoking for a long time [3]. Studies have revealed that increased rate of

*Address correspondence to this author at the Bahria University Medical and Dental College, Karachi, Pakistan. E-mail: dr.fsajjad@gmail.com tobacco smoking and gingival bleeding on probing are the early symptoms of gingivitis, a subject that is not dependent on significant signs of gingivitis and is now broadly applied to wards identifying lesions in periodontal complications [4]. Gingival bleeding is higher in non-smokers than in smokers [5]. This is attributed to the fact that there is vasoconstriction of the gingival cells or there is an occurrence of the keratinization of the gingivae among the smokers [6].

\section{METHODOLOGY}

The study population consisted of 169 participants who were chosen for this cross sectional survey from an urban population with ages of 15-65 years. Out of the total 169 participants, 130 were males and 39 were females. Their consumption behaviors were evaluated under groups of smoking, Chalia, Pan and Gutka. The periodontal investigation for the participants consisted of an evaluation of the gingival index, the plaque index, and the treatment needs of the community periodontal index [7].

\section{DATA ANALYSIS}

The SPSS version 16 was used in analyzing the results of the research to find out the relation between the participant's consumption behaviors, gingival scores, Community periodontal Index of Treatment Needs (CPITN) and the plaque indices. In addition, other elements such as gender, age and systematic health complications like hypertension, ischemic heart disease and diabetes mellitus were also investigated. 


\section{RESULTS}

Considering the participants, $11 \%$ (19) were smokers, $13 \%$ (22) used betel nut, 3\% (6) chewed tobacco, 3\% (5) used naswar, 2\% (4) used gutka, 1\% (1) used sheesha, 4\% used betel nut and sheesha, $1 \%$ used naswar and tobacco chewing and $60 \%$ were non-smokers. This is as shown by the pie chart below.

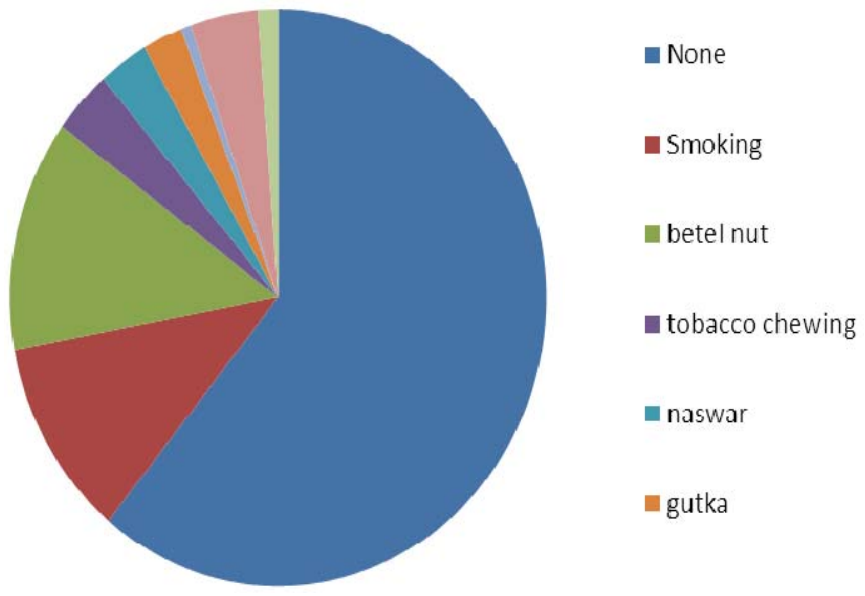

Fig. (1). Tobacco consumption of the participants.

Checking the periodontal status, $42 \%$ of the participants had healthy gums, $9 \%$ had gingival bleeding and $30 \%$ had gingival calculus (Fig. 1). In addition, 16\% of the participants had black band partially visible and one percent of the participants had a non-visibility of black band (Fig. 2). Considering the plaque score, $48 \%$ had debris index score 1 (soft debris covering not more then one-third of the tooth surface), $13 \%$ had debris index score to (soft debris covering more then one-third but not more then two-third of the expose tooth surface) and $5 \%$ had a debris index score of 3 (soft debris covering more then two-third of the expose tooth surface), $32 \%$ (55) of the population had no stains. $48 \%$ had cervical debris, $13 \%$ had $1 / 2$-tooth debris and 5\% had more than $2 / 3$ debris.

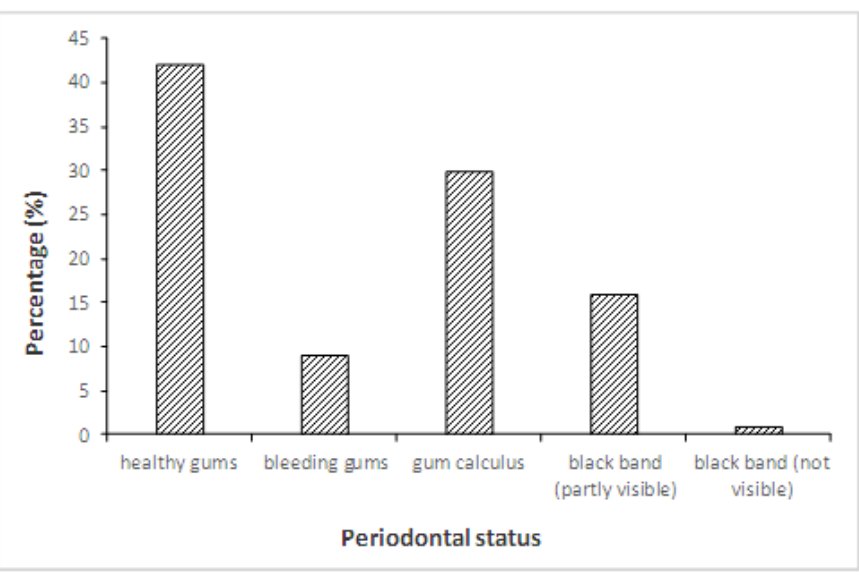

Fig. (2). Periodontal status of the participants.
According to the cross-tabulation data of the tobacco smoking and chewing habits, oral habits and age of the participants, smoking and betel nut consumption along with bad oral habits is higher in the participants falling in the age bracket of 15-25. With the increase in age, there is a decrease in tobacco consumption (Table $\mathbf{1}$ ).

Table 1. Cross-tabulation of tobacco smoking and chewing habits, oral habits of participants and age.

\begin{tabular}{|c|c|c|c|c|c|}
\hline & $\mathbf{1 5 - 2 5}$ & $\mathbf{2 6 - 3 5}$ & $\mathbf{3 6 - 4 5}$ & $\mathbf{4 6 - 5 5}$ & $\mathbf{5 6 - 6 5}$ \\
\hline Smoking & 8 & 4 & 3 & 3 & 1 \\
\hline Betel Nut & 10 & 6 & 5 & 0 & 1 \\
\hline Tobacco Chewing & 3 & 1 & 2 & 0 & 0 \\
\hline Naswar & 0 & 1 & 4 & 0 & 0 \\
\hline Gutka & 0 & 2 & 2 & 0 & 0 \\
\hline Sheesha & 1 & 0 & 0 & 0 & 0 \\
\hline $\begin{array}{c}\text { Betel nut and Sheesha } \\
\text { Naswar and Tobacco } \\
\text { chewing }\end{array}$ & 0 & 3 & 0 & 1 & 0 \\
\hline $\begin{array}{c}\text { Nail biting } \\
\text { chewing }\end{array}$ & 1 & 0 & 1 & 0 & 0 \\
\hline $\begin{array}{c}\text { Tongue thursting } \\
\text { Pencil chewing }\end{array}$ & 0 & 0 & 0 & 0 & 0 \\
\hline $\begin{array}{c}\text { Teeth grinding } \\
\text { Clenching }\end{array}$ & 2 & 0 & 0 & 1 & 0 \\
\hline Nail biting and teeth & 1 & 0 & 0 & 0 & 0 \\
\hline $\begin{array}{c}\text { Nail biting and pencil } \\
\text { gucking }\end{array}$ & 2 & 0 & 0 & 0 & 0 \\
\hline
\end{tabular}

\section{DISCUSSION}

The use of oral tobacco subjects the body to harmful substances like nicotine, that have adverse effects on the body [8]. These harmful substances get into an individual's oral cavity leading to the development of gingivitis [9]. Smoking not only inhibits the flow of blood to the periodontal tissues but it also generate oral keratosis that eventually leads to gingivitis [10]. However, there were contrary findings regarding the periodontal health complications. The results revealed that non-smokers had the highest rates of gingival bleeding compared to the smokers [11]. This is because to- 
bacco smoking affects the functioning of the periodontal tissues contributing to fewer actions on the gums. The high number of non-smokers experiencing gum bleeding is attributed to the fact that large number of people take more time before going for dental checkups. According to the findings, 32\% of the total participants never go for dental checkups, while $50 \%$ only go for checkups once a year. This implies that gingival complications are not discovered on time and if discovered, the irregular visiting to the dental clinics makes the management complicated which ultimately leads to periodontal pockets formation and bone destruction [12].

According to the findings, the effects of tobacco smoking and chewing are detrimental to the health of the users. The effects of tobacco are related to the increasing rates of some of the diseases like hypertension and diabetes mellitus [13]. Although the population was not sufficient to offer concrete evidence on this, other studies revealed that tobacco smoking has a positive correlation with the increase of these diseases [14]. Chances of developing periodontal complications were high among the smokers compared to non-smokers. This is because nicotine, a harmful chemical found in tobacco, produces cytotoxic substances that that favors the development of cavities [15].

\section{CONCLUSION}

It can be concluded that there is a relation between smoking and periodontitis. In addition, if the smoking duration is extended, it can have harmful effects on an individual's overall health.

\section{CONFLICT OF INTEREST}

Declared none.

\section{ACKNOWLEDGEMENT}

Declared none.

\section{REFERENCES}

[1] Sutton AL. Dental care and oral health sourcebook. $3^{\text {rd }}$ ed. United States: Omnigraphics; 2008. 647 p.

[2] Lapointe MM. Adolescent smoking and health research. New York: Nova Biomedical Books; 2008 [cited 2017 Mar 2]. 260 p. Available from: http://trove.nla.gov.au/version/41835990

[3] O'Donohue WT, Benuto LT, Tolle LW. Handbook of adolescent health psychology. New York, NY: Springer; 2013. 735 p. Available from: DOI: 10.1007/978-1-4614-6633-8

[4] Herman AI, Sofuoglu M. Cognitive effects of nicotine: genetic moderators. Addict. Biol., 2010; 15(3): 250-65. DOI: 10.1111/j.1369-1600.2010.00213.x

[5] Hirschfelder AB. Tobacco. Santa Barbara, Calif: Greenwood; 2010. 1- 264.

[6] Hoffman AC. The health effects of menthol cigarettes as compared to non-menthol cigarettes. Tob. Induc. Dis., 2011; 9 (Suppl 1): S7. DOI: 10.1186/1617-9625-9-S1-S7

[7] Ashcroft RE. The philosophy of public health. J. Public Health, 2010; 32(1): 141. DOI: https://doi.org/10.1093/pubmed/fdp106

[8] Bellenir K. Tobacco information for teens [Internet]. $3^{\text {rd }}$ ed. United States: Omnigraphics; 2007. 1- 425.

[9] Blank MD, Nasim A, Hart A, Eissenberg T. Acute effects of cigarillo smoking. Nicotine Tob. Res., 2011; 13(9): 874-9. DOI: https://doi.org/10.1093/ntr/ntr070

[10] Dawson A, Verweij M. Ethics, prevention, and public health. England: Oxford University Press; 2007.

[11] Adams S, Attwood AS, Munafo MR. Effects of nicotine and nicotine expectancy on attentional bias for emotional stimuli. Nicotine Tob. Res., 2015; 17(6): 697-703. DOI: 10.1093/ntr/ntu219

[12] Porterfield J. Tobacco [Internet]. New York: Rosen Central; 2008 [cited 2017 Apr 12]. Available from: https://palliserlibrary.ca/spm/search/item/368549

[13] Colvin PJ, Mermelstein RJ. Adolescent's smoking outcome expectancies and acute emotional responses following smoking. Nicotine Tob. Res., 2010; 12(12):1203-10. DOI: 10.1093/ntr/ntq169

[14] Alberg A. Cigarette smoking: health effects and control strategies. Drugs Today, 2008; 44(12): 895-904. DOI: 10.1358/dot.2008.44.12.1308898

[15] Oni AO, Eweka AO, Otuaga PO. Smoking: its health effects and cessation. Internet. J. Nutr. Wellness, 2008; 6(1): 8. 